tones into a regular sequence. After hearing the morning stars singing together in their glory for so long, it was no wonder that they had influenced his character and made him to his many admirers only a little lower than the angels. The Rector of the College, Mr. Tizard, afterwards presented Prof. Fowler with an illuminated address, together with a writing desk, chair and a silver tea-tray from past and present colleagues.

\section{New Science Buildings at Cambridge}

Four important additions to the scientific laboratories at Cambridge will be available for public inspection on October 22, the occasion of H.M. the King's visit to open the new University Library. All, however, will have been in use since the commencement of the Michaelmas term, so that there will be no ceremony. These buildings, in so far as they are concerned with research, are paid for under a generous scheme agreed to with the Rockefeller Trustees, but, in addition, the University has built new teaching laboratories for the Zoological Department, the two top floors and part of the basement of its new school representing the Rockefeller contribution. The new wing for physiology is a building about $70 \mathrm{ft}$. by $50 \mathrm{ft}$. and $60 \mathrm{ft}$. high with five floors, of which the lowest is a theatre to hold 280 students. The first floor is devoted to pharmacology, and the second to chemical aspects of physiology, while the top floors represent advanced teaching and research; this wing gives the Department a total accommodation for more than forty research workers. Botany has received a 60 -ft. extension of its previous building. The addition comprises an advanced lecture room and library extension on the ground floor. Half of the first floor is devoted to palæobotany, while the remainder of this floor and the second floor form a Sub-Department of Mycology, the top floor falling to advanced physiology. Agriculture has a new building largely devoted to offices, etc., but the Rockefeller scheme here is invaluable in the assistance given to research in animal physiology, in soil research and in statistics, among other subjects. Zoology retains its old Museum wing unaltered, but otherwise has an entirely new building with novel features that are likely to cause it to be most extensively visited on October 22. Rooms have been assigned in it to fifty-seven workers engaged in research work.

\section{The Male Sex Hormone}

Organic chemists are well accustomed to spectacular results from the researches of Prof. L. Ruzicka and his school. Yet the artificial production of the male sex hormone recorded in the October number of the Helvetica Chimica Acta by Ruzicka, Goldberg, Meyer, Brüngger and Eichenberger probably transcends in interest any previous publication from the Zurich laboratories. Adopting the hypothesis of Butenandt, who first isolated and charac. terised the testicular hormone, that this substance is a hydroxyketone closely related to the sterols, Ruzicka and his collaborators examined the neutral fractions arising from the chromic acid oxidation of the acetate of dihydrocholesterol and some of its stereoisomerides. The removal of the sterol side chain by such oxidations has long been used for the identification of the side chain, but previous investigators had been unable to isolate the major fragment of the molecule. This has been achieved by Ruzicka, and the hydroxyketone resulting from epidihydrocholesterol proved to be completely identical with the male hormone (androsterone) isolated by Butenandt. By this simple experiment, the structure of a complex natural product has been completely elucidated and its stereochemical relationship to the sterols established. Apart from speculation, the only previous chemical knowledge of the hormone was that it was a saturated hydroxyketone of the probable formula $\mathrm{C}_{19} \mathrm{H}_{30} \mathrm{O}_{2}$. It is unfortunate that this conversion of cholesterol into androsterone should be described by the investigators as a 'synthesis'.

THE simplest biological test for the male hormone is its effect in promoting comb-growth in capons, and in this respect the artificial substance proved as effective as the natural hormone. A remarkable feature is the specificity of the hormone. Of the four stereoisomeric hydroxyketones obtained by the oxidation of dihydrocholesterol, epidihydrocholesterol, coprosterol, and epicoprosterol, those from the last two compounds had no influence on the comb-growth of capons in daily doses of $1000 \gamma$; that from dihydrocholesterol required daily doses of $500 \gamma$ for combgrowth, whereas the artificial hormone (from epidihydrocholesterol) gave a response with daily doses of $70 \gamma$.

\section{The Chemist and Warfare}

Mr. J. Davidson PratT, secretary and general manager of the Association of British Chemical Manufacturers, addressing the Glasgow Section of the Society of Chemical Industry on October 5, discussed the part to be played by the chemist in schemes of national defence against attack from the air. $\mathrm{He}$ said that, in spite of the Geneva Protocol prohibiting the use of gas in war, it is necessary that the general public should be instructed in methods of defence, since some nations in signing the Protocol have made it clear that they would use gas if an adversary used it first. Gas used against an uninstructed civil population has a demoralising effect, but the publication of highly alarmist articles on the subject of poison gas attacks from the air by people whose knowledge of the subject is very limited is most undesirable. Mr. Pratt referred to the work which would fall to the chemist in the event of an air raid. He would have to be on the spot to identify the gas used, and would be required to decide quickly whether an area would require to be decontaminated or not, as some types of gas would be quickly swept away by the wind while other types would persist for a considerable length of time. The best method of defence for the civil population is the provision of gas-proof shelters, and every building should contain a gasproof room. The chemist's advice would be required in selecting and fitting these rooms. 